\title{
PROUCA-UFT-TOCANTINS: UM DESAFIO ALICERÇADO NO COMPROMISSO, NAS PARCERIAS INSTITUCIONAIS E NA POSSIBILIDADE DE UMA EDUCAÇÃO COM QUALIDADE SOCIAL
}

\author{
Valdirene Gomes dos Santos de Jesus ${ }^{1}$, Marilene Andrade Ferreira Borges ${ }^{2}$, George França ${ }^{3}$, \\ Maria Elizabeth Bianconcini de Almeida ${ }^{4}$
}

\author{
${ }^{1}$ Universidade Federal do Tocantins (jesuseval@uft.edu.br - Bolsista CNPq), ${ }^{2}$ Universidade \\ Federal de Ouro Preto (marilene@ @ead.ufop.br), ${ }^{3}$ Universidade Federal do Tocantins \\ (george.f@uft.edu.br, ${ }^{4}$ Pontifícia Universidade Católica de São Paulo - PUC/SP \\ (bbalmeida@uol.com.br).
}

\begin{abstract}
This article presents the PROUCA Tocantins - UFT: training for use of Digital Technologies for Information and Communication - TDIC in school. This project proposes to empower teachers and administrators of public schools in the state of Tocantins pedagogical use of TDIC. Its purpose is to enable digital inclusion school, pedagogical and technological appropriation of TDIC, as language from the educational laptops, the possibility of expanding access to quality education social. It is present in 74 cities in the state of Tocantins, serving 135 schools that joined the training plan proposed by the Federal University of Tocantins, a total of 1.800 course participants, among staff training, teachers and school managers. For its realization, were established several institutional partnerships that articulate seeking to ensure their implementation. It is a project in which the relations between training providers and course participants in training are rooted in work participation, cooperation, trust and citizenship .
\end{abstract}

\section{RESUMO}

O presente artigo apresenta o PROUCA Tocantins - UFT: formação para uso das Tecnologias Digitais de Informação e Comunicação - TDIC na escola. Esse projeto propõe capacitar professores e gestores das escolas municipais do estado de Tocantins para uso pedagógico das TDIC. Sua finalidade é possibilitar inclusão digital escolar, apropriação tecnológica e pedagógica das TDIC, enquanto linguagem a partir dos laptops educacionais, ampliando a possibilidade de acesso a uma educação com qualidade social. Está presente em 74 municípios do estado do Tocantins, atendendo 135 escolas que aderiram ao plano de formação proposto pela Universidade Federal do Tocantins, num total de 1.800 cursistas, entre a equipe de formação, professores e gestores das escolas. Para sua realização, foram estabelecidas várias parcerias institucionais que se articulam buscando garantir sua execução. É um projeto em que as relações estabelecidas entre as entidades formadoras e os cursistas em formação se alicerçam em um trabalho de participação, cooperação, confiança e cidadania.

\section{INTRODUÇÃO}

Um dos pilares da educação com qualidade social está na formação dos profissionais da educação que, ao terem acesso a programas de formação continuada, reveem conceitos, conhecem novas teorias, produzem conhecimentos novos que permitem iluminar as próprias práticas, ser autores e coautores do conhecimento e promover construção de novos 
conhecimentos pelos seus alunos. Esses profissionais precisam promover um ensino comprometido com o desenvolvimento do potencial humano, possibilitando ao aluno a aprendizagem, o exercício dos direitos civis, políticos, sociais e do direito à diferença, "uma educação de qualidade como um direito fundamental, é antes de tudo, relevante, pertinente e equitativa" (BRASIL, 2010, p. 2). A relevância pode ser traduzida, no espaço da escola, enquanto promoção de aprendizagens significativas; a pertinência, como possibilidade de atender às necessidades e às características dos alunos de diferentes contextos sociais e culturais, com capacidades e interesses diversos; e a equidade significa a importância de tratar de forma diferenciada aqueles que se apresentam como desiguais no ponto de partida, porém com direitos à construção de conhecimento e aprendizagens equiparáveis, garantindo a todos igualdade de direito à educação.

As Diretrizes Curriculares Nacionais Gerais para a Educação Básica apontam a importância e a premência da inserção e do uso das tecnologias digitais nos processos escolares, pontuando que elas devem perpassar a proposta curricular desde a educação infantil até o ensino médio, "imprimindo direção aos projetos político-pedagógicos" (BRASIL, 2010, p. 6). Além disso, é necessário evidenciar o acesso dos alunos às TDIC enquanto instrumentos contemporâneos de uma sociedade digital que devem "estar inseridas, integradas aos processos educacionais, agregando valor à atividade que o aluno ou o professor realiza" (ALMEIDA; VALENTE, 2011, p. 74).

Entendemos e concordamos com Almeida e Valente (2011) de que o processo de integração das tecnologias digitais ao currículo está relacionado à formação continuada dos educadores. Ao mesmo tempo em que o professor aprende, ele também se certifica na prática de que as teorias estudadas e os conhecimentos desenvolvidos no processo de formação lhes permitem modificar suas práticas pedagógicas, ressignificando-as em outros contextos, espaços e tempos. É um percurso que lhe permite também se autoavaliar e compreender que vivemos um momento em que a geração de crianças e jovens que frequentam as escolas e com as quais ele trabalha são, na sua maioria, denominados como nascidos digitais. Para eles, as tecnologias não apresentam dificuldade de manuseio, eles não sentem receio na operacionalização dos equipamentos que fazem parte de sua cultura. O que eles esperam, querem e têm direito é de uma escola que seja contemporânea desse momento digital, e que as TDIC trabalhadas e ressignificadas no interior das escolas sejam acrescidas àquelas como as quais eles já lidam no cotidiano e que lhes permitem aprender de forma mais significativa e prazerosa os conteúdos curriculares tanto no que diz respeito ao currículo prescrito como ao currículo realizado na prática pedagógica. 
Mas como promover o acesso dos professores às tecnologias digitais possibilitando-lhes a reconstrução e a construção de novas práticas ou inovações que acenem possibilidades reais de tornar mais eficientes os processos de ensino e aprendizagem?

O presente artigo apresenta o PROUCA Tocantins - UFT: formação para uso das Tecnologias Digitais de Informação e Comunicação - TDIC na escola, que está em desenvolvimento em 74 municípios no estado do Tocantins. É um programa em que as relações estabelecidas entre as entidades formadoras e os cursistas em formação se alicerçam num trabalho de participação, cooperação, confiança e cidadania.

\section{DO PRÉ-PILOTO À EXPANSÃO EM ESCOLAS MUNICIPAIS: ACERTANDO OS PASSOS AO CAMINHAR}

Em 2007, o estado do Tocantins iniciava a incursão da escola pública no programa Um Computador por Aluno (UCA). O Colégio Estadual Dom Alano Marie Du Noday havia sido selecionado para receber os laptops educacionais e fazer parte de projeto experimental a ser desenvolvido no país. Participaram desse programa cinco escolas públicas de diferentes Estados. Sem ter em quem se espelhar, a escola aceitou o desafio de fazer das tecnologias digitais meios para melhorar os processos de ensino e aprendizagem. Estabeleceu parcerias e, com o suporte teórico-pedagógico de instituições como a Pontifícia Universidade Católica de São Paulo, PUC-SP, procurou rever suas práticas pedagógicas buscando alternativas que expressassem a contemporaneidade nos diversos usos das tecnologias digitais. Entre erros e acertos, a escola avançou, professores, gestores e, de forma especial, alunos tiveram a oportunidade de estudar em uma escola onde os laptops educacionais estavam conectados à internet. Diferentes formas de ensinar e de aprender foram criadas por alunos e professores, gerando impactos na gestão da sala de aula, das tecnologias nos processos de ensino e de aprendizagem. A escola passou a ser uma referência para a comunidade local e espaço de pesquisa. O uso dos laptops educacionais por alunos e professores foi objeto de quatro dissertações de mestrado, Mendes (2008), Mascarenhas (2009), Silva (2009), Rosa (2010), uma tese de doutorado Neiva (2013) e um relatório para o Banco Mundial sobre o uso dos laptops educacionais em escolas públicas.

Em 2010, após avaliação e análise das escolas que participaram do pré-piloto, o governo federal iniciou a fase II do Programa um Computador por Aluno (PROUCA), denominada Piloto. Dessa fase, participam pouco mais de 300 escolas públicas no país, sendo 10 escolas em cada Estado da Federação e todas as escolas de seis municípios. 
Os laptops, denominados de laptops educacionais, têm características especiais de hardware e software para uso em educação, que permitem portabilidade, interoperabilidade, acessibilidade, conectividade, imersão e mobilidade e utilizam o sistema operacional Linux. Eles foram distribuídos na proporção de um computador para cada aluno, isto é, 1:1.

Para a qualificação de professores e gestores nas escolas contempladas com o projeto, utilizou-se o "Projeto UCA Formação Brasil". Entre seus objetivos, o projeto buscava "criar e socializar novas formas de utilização das tecnologias digitais nas escolas públicas brasileiras para ampliar o processo de inclusão digital escolar e promover o uso pedagógico das tecnologias de informação e comunicação" (BRASIL, 2009, p. 1).

No estado do Tocantins, o processo de formação foi desenvolvido a partir de uma rede formada por professores pesquisadores da PUC-SP, que compõe a IES global, por professores formadores da Universidade Federal do Tocantins - UFT, que é a IES local, em parceria com professores formadores e tutores das secretarias de educação estadual e municipais.

Para implantação e implementação do processo de formação, a equipe utilizou várias estratégias, como: criação da coordenação do UCA na escola; criação e formação do aluno monitor; formação em rede, articulando IES local, IES global, SEDUC e escola; reuniões virtuais via Skype; criação de um ambiente virtual colaborativo de discussão; encontros presenciais; seminários regionais e o I Seminário Estadual Programa UCA Tocantins: práticas pedagógicas com uso do laptop educacional, Palmas-TO (com participação dos cursistas das 10 escolas contempladas, apresentação de 52 trabalhos em formato de pôsteres que representam as experiências de sucesso desenvolvidas nas escolas com o uso do laptop educacional); além da apresentação de 22 trabalhos, no III Web Currículo em 2012. O processo de formação qualificou 254 profissionais da educação entre professores, gestores e especialistas em educação.

Como etapa final do processo de formação do PROUCA/2012, foi realizado o Fórum Tecnologia, Educação e Mobilidade da UFT. A intenção foi promover debate, reflexões e socialização de experiências de uso das TDIC nos processos de ensino e aprendizagem. $\mathrm{O}$ foco foi a integração das tecnologias ao currículo, a mobilidade e a portabilidade das tecnologias e do conhecimento. Com a duração de dois dias, o Fórum contou com conferências, mesas redondas, estudos de aprofundamentos e oficinas. O público básico do Fórum foi formado por professores, gestores, secretários municipais de educação, técnicos das secretárias de educação, alunos dos cursos das licenciaturas, professores do ensino superior. Teve uma média de 300 participantes. Nesse trabalho, foram apresentados alguns resultados da integração das TDIC ao currículo, tendo como referência as práticas pedagógicas 
desenvolvidas e socializadas por professores e gestores das escolas participantes do PROUCA-TO.

Durante o período de realização do projeto, consolidou-se a formação da rede de blogs das escolas, houve a participação da equipe de formadores e professores em vários eventos nacionais e internacionais com apresentação e socialização de trabalhos realizados nas escolas. Também se publicou artigo em livro sobre o projeto UCA e inseriram-se duas escolas participantes no Projeto $\mathrm{CNPq}$ “O currículo do século XXI: a integração das TIC ao currículo - inovação, conhecimento científico e aprendizagem” (ALMEIDA, BARRETO, JESUS, 2012)

Em 2011-2013, duas escolas do estado (EE Presidente Costa e Silva e EE Beira Rio) participaram do Projeto CNPq "O currículo do século XXI: a integração das TIC ao currículo - inovação, conhecimento científico e aprendizagem" (ALMEIDA, BARRETO, JESUS, 2012) que dentre seus objetivos destacava,

[...] identificar as contribuições e dificuldades das ações de formação e das práticas realizadas nas escolas participantes do PROUCA, as mudanças desenvolvidas no currículo e nas práticas educativas, os indícios de inovação educativos evidenciados, bem como desenvolver um processo de intervenção contextualizado que possa impulsionar o uso do laptop de modo que este traga contribuições significativas ao desenvolvimento do currículo. (p.4)

As duas escolas participantes do projeto atestam as consideráveis contribuições dos laptops para potencializar as práticas escolares, consonantes ao paradigma estabelecido no Projeto CNPq onde a escola é concebida como,

Um centro de aprendizagem e de ensino, que proporciona aos alunos, a partir de suas necessidades, a participação em debates de ideias e reflexões, levando-os a superar os saberes socialmente construídos por um saber mais crítico, possibilitando-lhes transformarse em sujeitos de suas próprias histórias (ibid., p. 6).

O estudo realizado na EE Beira Rio permitiu evidenciar os avanços e os entraves encontrados durante o tempo de formação. Ao observar-se o ponto de partida da escola, é possível evidenciar que: a) a escola fez a inclusão digital de seus alunos e, em parte, das respectivas famílias; b) possibilitou a troca de experiência e um repensar na relação professor aluno; c) conseguiu, a partir dos projetos elaborados pelos professores e desenvolvidos com os alunos, para uso da tecnologia na escola, despertar o professor para perceber e se solidarizar com a situação social dos alunos; d) compreendeu melhor o perfil de seus alunos; e) trabalhou a valorização dos alunos, enquanto sujeitos sociais do campo; f) trabalhou a autoestima e o sentido de pertencimento ao meio e difundiu a ideia de que eles (alunos) são sujeitos sociais; g) possibilitou aos alunos o uso dos aplicativos do laptop para acesso à informação, à produção textual, a releituras, ao uso das linguagens textuais, imagéticas, 
musicais, filmagens e trabalhos de autoria, pois os alunos, a partir dos estudos reflexivos dos textos, foram produzindo e socializando suas produções. Dessa maneira, é possível afirmar que a presença dos laptops na escola desencadeou uma mudança não somente dentro da escola, como também em toda a comunidade escolar, favorecendo a tão almejada inclusão digital desta nação.

O estudo realizado na EE Costa e Silva permitiu identificar as contribuições e as dificuldades das ações de formação, as mudanças desenvolvidas no currículo e nas práticas educativas feitas na escola. Permitiu também identificar contribuições significativas para o desenvolvimento do currículo.

Entre as dificuldades mais relevantes, destacam-se os problemas de infraestrutura: a organização e adequação dos espaços físicos, adequação da rede lógica, os problemas técnicos de recargas das baterias dos laptops azuis.

Em relação à gestão de pessoas, destacam-se como dificuldades: a rotatividade dos professores durante o processo de formação, a reorganização do processo de formação para atender aos novos professores, a organização e a falta de disponibilidade de horários para a participação na formação, a articulação e a interação entre professores e alunos.

As contribuições mais relevantes referem-se aos benefícios obtidos pelo processo de formação que possibilitou a professores e alunos utilizar os laptops em espaços escolares e não escolares. $\mathrm{O}$ acesso aos laptops, a mobilidade do laptop, as formas de construção do conhecimento com o uso de múltiplas linguagens, a portabilidade, a motivação de alunos, professores e gestores para utilizar as TDIC a favor dos processos de gestão de ensino e aprendizagem, todos esses elementos desencadearam mudanças positivas nas práticas pedagógicas realizadas na escola.

Observamos ainda que, apesar das dificuldades encontradas, os profissionais da escola têm desenvolvido práticas pedagógicas com o uso dos laptops em distintos espaços. Utilizam diversas linguagens midiáticas, com estratégias pedagógicas diversificadas, o que nos possibilita identificar a ocorrência da mobilidade das tecnologias (nos vários espaços), da informação (que não está restrita aos livros didáticos e à sala de aula, com uso das redes de web, nas comunidades, nos sujeitos sociais) e do conhecimento com a inserção da tecnologia. Criaram-se novas dinâmicas de construção do conhecimento, de pesquisa, de planejamento, de investigação, registro dos resultados dos trabalhos e de socialização desses conhecimentos.

Foi possível constar, nos diferentes espaços de registros, que alunos, professores e gestores testemunham inúmeros pontos positivos do projeto que provocaram impactos na escola, nos professores e em seus processos de ensinar, nos alunos e nas suas formas de 
aprender. E, nesse sentido, Almeida e Valente (2011, p. 31) pontuam que é importante utilizar as TDIC no contexto da escola:

[...] para potencializar práticas pedagógicas que propiciem um currículo voltado ao desenvolvimento da autonomia do aluno, na busca e na geração de informações significativas para compreender o mundo e atuar em sua reconstrução, no desenvolvimento do pensamento crítico e autorreflexivo do aluno, de modo que ele tenha capacidade de julgamento, autorrealização e possa atuar na defesa das ideias de liberdade responsável, emancipação social e democracia.

Destaca-se também os 18 projetos desenvolvidos na escola em 2011, 2012, 2013. Esses projetos tiveram seus resultados socializados no site e no blog da escola e nos eventos estaduais e nacionais. Destacamos que criação do site e do blog da escola são resultados do desenvolvimento da formação do Projeto UCA na escola.

\subsection{PROUCA TOCANTINS - UFT: FORMAÇÃO PARA USO DAS TECNOLOGIAS DIGITAIS DE INFORMAÇÃO E COMUNICAÇÃO - TDIC NA ESCOLA}

Em 2012, o governo do estado do Tocantins instituiu o Programa Tocantins ConectadoUm Computador por Aluno e adquiriu 75.648 laptops educacionais que estão sendo distribuídos entre as escolas estaduais e municipais.

Os municípios que receberam os laptops do governo, por intermédio da União dos Dirigentes Municipais (UNDIME), procuraram a Universidade Federal do Tocantins - UFT para que fosse feito o processo de formação dos professores e dos gestores das escolas municipais para o uso dos laptops educacionais. Com o firme propósito de contribuir com as escolas que receberam os laptops, a universidade, por meio da Pró-Reitoria de Extensão, criou o PROUCA Tocantins-UFT estabelecendo parcerias para viabilizar o projeto. São parceiros o Ministério de Educação e Cultura (MEC); a Pontifícia Universidade católica de São Paulo (PUC-SP); a Universidade Federal de Ouro Preto (UFOP); a União dos Dirigentes Municipais do Tocantins (UNDIME-TO); e Secretaria de Educação do Estado do Tocantins (SEDUC). O projeto, em desenvolvimento desde julho/2013, está presente em 74 municípios do Estado, atendendo a 135 escolas que aderiram ao plano de formação proposto pela Universidade Federal do Tocantins, num total 1.800 cursistas entre a equipe de formação, professores e gestores das escolas.

Para a execução da proposta de formação voltada ao uso pedagógico das TDIC nas escolas, foram planejadas as seguintes ações que estão sendo implantadas e implementadas: constituição da equipe de coordenação da UFT e instituições parceiras responsáveis pela criação do curso e capacitação em rede; elaboração da proposta de formação, acompanhamento e avaliação do processo de formação dos profissionais das escolas que 
fazem parte do PROUCA; constituição de equipe para formação in loco e em rede; capacitação e acompanhamento dos profissionais das escolas municipais que fazem parte do PROUCA Tocantins-UFT; implementação do processo de pesquisa, sobre o uso pedagógico das TDIC no contexto das escolas visando a identificar práticas pedagógicas inovadoras com o laptop educacional e desenvolver referenciais da mudança curricular necessária à escola no contexto da sociedade do conhecimento.

\subsection{ORGANIZAÇÃO DA REDE DE FORMAÇÃO}

Como forma de organização do projeto, foram criadas coordenações que, apesar de suas atribuições específicas, fazem parte de uma única rede: coordenação geral e vicecoordenação; coordenação de campus, coordenação pedagógica, coordenação tecnológica, coordenação de avaliação, coordenação de articulação política, coordenação de conteúdo, coordenação de formação de formadores, orientador do projeto, colaboradores do projeto, suporte técnico, tutores, coordenador do UCA na escola, SEMED, escolas, que estão articuladas para viabilizar a execução do projeto. A figura abaixo apresenta a forma de organização da rede de formação do projeto

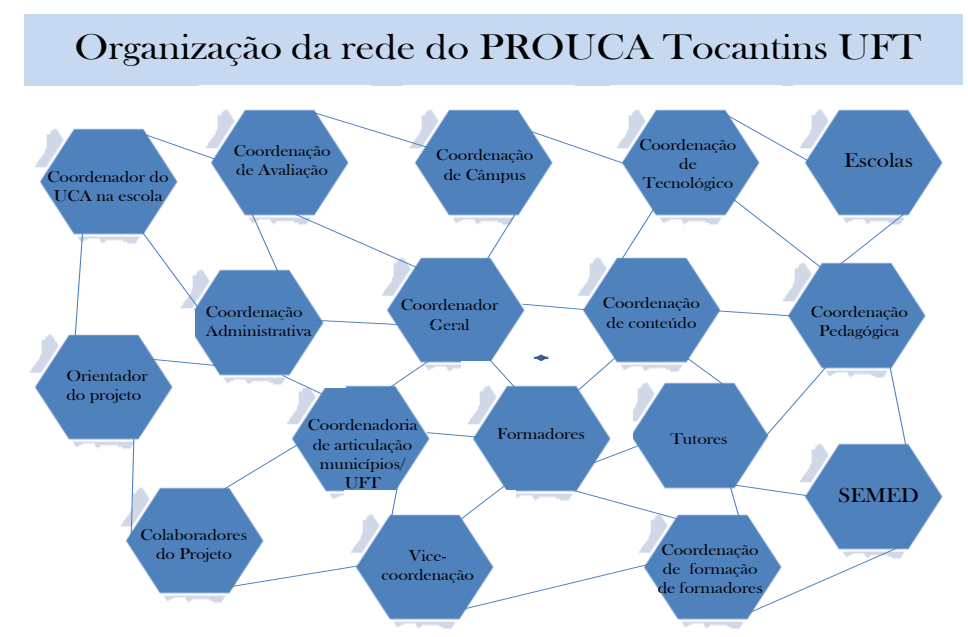

Figura 01: Organização da rede PROUCA Tocantins UFT

Fonte: Produção de Jesus (2013)

Para uma melhor gestão do projeto, os municípios foram nucleados a partir da sua proximidade em relação aos sete campi: UFT-Araguaína, Arraias, Gurupi, Miracema, Palmas, Tocantinópolis, Porto Nacional, que formam as regionais do projeto. A equipe de formação foi organizada e distribuída tendo em vista o número de escolas e cursistas da regional. Compõem a rede de formação por campus: o coordenador do campus, os formadores, os tutores, os professores, os gestores, os coordenadores do UCA na escola. A figura abaixo 
apresenta o processo de nucleação dos municípios, a formação das regionais e a distribuição da equipe de formação.

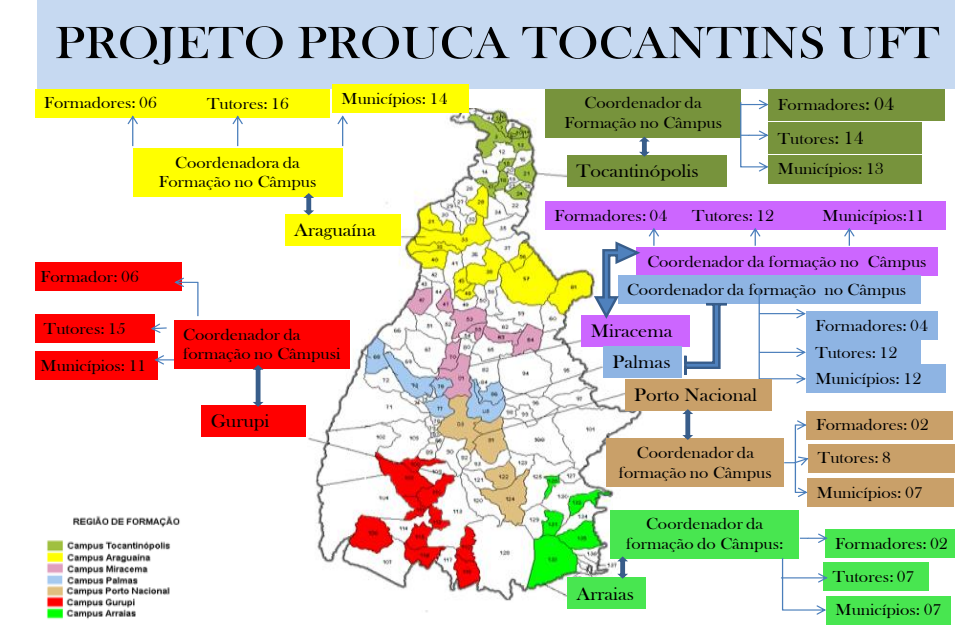

Figura 02: Distribuição da equipe de Formação PROUCA Tocantins UFT/Por Câmpus Fonte: Produção de Jesus (2013)

Os cursos de formação em parceria com PUC-SP estão organizados em parte presencial, com encontros presenciais, no início de cada etapa de formação, e parte a distância, quando então as atividades são realizadas no ambiente virtual de aprendizagem Moodle versão 2.4. Têm como conteúdos básicos os módulos produzidos pela equipe do GTUCA, depurados após as formações iniciais ocorridas desde 2009, recontextualizados para a realidade das escolas municipais de Tocantins e acrescidos de outras atividades consideradas relevantes pela equipe de formação de formadores da PUC-SP. Em consonância com os princípios do Projeto UCA (BRASIl, 2009), os conteúdos englobam três dimensões que se encontram imbricadas em seu desenvolvimento: Tecnológica: apropriação e domínio dos recursos tecnológicos; Pedagógica: uso dos laptops nos processos de ensinar e aprender, bem como na gestão de tempos, espaços e relações entre os protagonistas da escola, do sistema de ensino e da comunidade externa; Teórica: busca de articulação de teorias educacionais que permitem compreender criticamente o uso em diferentes contextos e reconstruir as práticas pedagógicas e de gestão da sala de aula e da escola.

Para a realização do processo de formação em parceria com PUC-SP, foram montados dois grupos distintos: Grupo 1: formado pelos coordenadores de campus, formadores e tutores, num total de 156 cursistas estão fazendo o Curso de Formação dos Formadores com carga horária de 180 horas. Essa formação é realizada Pela Pontifícia Universidade Católica de São Paulo, desenvolvidos em três etapas: Etapa 1- O mundo digital: apropriação tecnológica e o PROUCA - 40h; Etapa 2- O currículo e as TDIC: elaboração de projetos - 80 h; Etapa 3- Depurando o projeto - 60h; Grupo 2: formado por professores, gestores e 
coordenador do UCA da escola - num total de 1.744 estão fazendo o curso de formação de professores - também em três etapas, com uma carga horária de140 horas que foram assim distribuídas: Etapa1- O mundo digital: apropriação tecnológica e o PROUCA - 30h; Etapa 2O currículo e as TDIC: elaboração de projetos - $60 \mathrm{~h}$; Etapa 3- Depurando o projeto - 50h. O processo de certificação está a cargo da Pró-Reitoria de Extensão e Cultura da UFT.

Os dois grupos em formação iniciaram o processo em tempos diferentes, com uma diferença de aproximadamente trinta dias, primeiro os formadores e depois os professores, uma vez que são os formadores que acompanham e subsidiam o processo de formação dos professores e gestores.

O processo de avaliação é realizado no decorrer do curso, e a análise dos dados coletados subsidia o realimento das atividades de formação.

\section{CONCLUSÃO}

Entendemos que é preciso capacitar professores e gestores das escolas municipais do estado de Tocantins para uso pedagógico das TDIC. Uma forma de possibilitar-lhes, a partir dos laptops educacionais, a inclusão digital escolar, a apropriação tecnológica e pedagógica das TDIC enquanto linguagem e instrumento estruturante do currículo. Num desdobramento, os professores e gestores colocariam esses conhecimentos a favor dos processos de ensino e aprendizagem dos alunos das escolas tocantinenses, ampliando-lhes a possibilidade de acesso a uma educação com qualidade social. Compreendemos e partimos para o desafio assumido por toda a equipe de trabalho do PROUCA Tocantins-UFT que tem contribuído de forma significativa para ampliar os aspectos considerados na concepção do projeto e dar vida nas ações de formação junto às escolas à proposta de formação elaborada, bem como atribuir significado à avaliação do mesmo na perspectiva de avaliação formadora.

\section{REFERÊNCIAS BIBLIOGRÁFICAS}

ALMEIDA, M. E. B.; VALENTE, José A. Tecnologias e currículo: trajetórias convergentes ou divergentes? São Paulo: Paulus, 2011.

ALMEIDA, M. E. B.; BARRETO, G. O.; JESUS, V. G. S. O currículo da escola do século XXI: a integração das TIC ao currículo: inovação, conhecimento científico e aprendizagem. In: FERRENTINI, F. S; ELIA, M. F.(orgs.). Projeto um computador por aluno: pesquisas e perspectivas- Rio de Janeiro: NCE/UFRJ, 2012. pp. 259 - 270. Disponível em: <http://www.nce.ufrj.br/ginape/livro-prouca/> Acesso em 8 out. 2013.

BRASIL, Ministério da Educação. Secretaria de Educação a Distância. UCA: Projeto um computador por aluno. Brasília, 2009.

BRASIL. MEC. Resolução CNE/CEB no 4, de 13 de julho de 2010. Define Diretrizes Curriculares Nacionais Gerais para a Educação Básica. Brasília, 2010. 
MASCARENHAS, Paulo Rogério Rocha. Inclusão digital dos alunos do Colégio Dom

Alano Marie Du Noday: o Projeto UCA em Palmas (TO). Brasília: UnB, 2009. Dissertação (Mestrado em Educação), Faculdade de Educação, Universidade de Brasília, 2009. Disponível em: http://repositorio.unb.br/bitstream/10482/4829/1/2009_PauloRogerioRochaMascarenhas.

pdf> Acesso em: 16 jun. 2013.

MENDES, Mariza. Introdução do laptop educacional em sala de aula: indícios de mudanças na organização e gestão da aula. São Paulo: PUC-SP, 2008. Dissertação (Mestrado em Educação: Currículo), Pontifícia Universidade Católica de São Paulo, 2008.

Disponível em: <http://www.sapientia.pucsp.br/tde_busca/arquivo.php?codArquivo=7958>

Acesso em: 16 jun. 2013.

MOREIRA, S. R. da S. Análise de reações de professores face à introdução do computador na educação: o caso do Projeto UCA - um computador por aluno no Colégio

Estadual Dom Alano Marie Du Noday (TO). Brasília: UnB, 2010. Dissertação (Mestrado em Educação), Universidade de Brasília, 2010.

NEIVA, Sônia M. S. F. O laptop educacional em sala de aula: práticas pedagógicas construídas. São Paulo: PUC SP, 2013. Tese (Doutorado em Educação: Currículo), Pontifícia Universidade Católica de São Paulo.

SECRETARIA ESTADUAL DE EDUCAÇÃO DO TOCANTINS. Programa Tocantins ConectadoUm Computador por Aluno. Palmas-TO, 2011.

SILVA, Martha H. da. Repercussões do Projeto Um Computador por Aluno no Colégio Estadual Dom Alano Marie Du Noday (TO). 2009.141f. Dissertação (Mestrado em Educação), Universidade de Brasília.

PONTIFÍCIA UNIVERSIDADE CATÓLICA DE SÃO PAULO. Projeto CNPq “O currículo do século XXI: a integração das TIC ao currículo - inovação, conhecimento científico e aprendizagem”. São Paulo, 2012.

UNIVERSIDADE FEDERAL DO TOCANTINS. Projeto básico do PROUCA - Um Computador

Por Aluno: Formação para uso das tecnologias digitais de informação e comunicação - TDIC. 2013. 